\title{
ENSINO PROFISSIONAL DE ECONOMIA
}

\author{
Candido Motta Filho \\ Ministro de Educação e Cultura \\ Professor da Universidade de São Paulo
}

O cinquentenário da Lei $n .^{\circ} 1.339$ envolve, para júbilo e orgulho nosso, o cinquentenário da instituição no país do ensino profissional de economia e administração.

Nada mais significativo para nós do que êsse aspecto da lei, ao mesmo tempo previdente e audaciosa.

O que, a respeito, ensinávamos nos cursos jurídicos, nos envoltórios do direito administrativo e da economia política. tinha como finalidade primordial a compreensão dos problemas "sub specie juris".

A partir de 1905 a situação é outra. Os nossos maiores tiveram a antevisão das transformações de base no país e a convicção de que a construção de seu edifício social dependeria dos conhecimentos seguros da economia e da ciência da administração.

E agora, quando estamos todos como que cercados pelos problemas econômicos do Estado moderno, sentimos o benefício dessa lei admirável, que glorifica seus autores e nos impulsiona para melhores dias.

De fato, o curso superior de comércio, do princípio do século, mantido pela Academia de Comércio do Rio de Janeiro e

Palestra proferida na Semana do Economista de 1955, sôbre "O cinquentenário da oficialização do ensino de economia e administração no Brasil. Evolução do curso e importância da carreira". 
pela Escola Prática de Comércio da Fundação Álvares Penteado, em prosseguimento de estudos para os contadores que habilitava o seu curso geral, visava ao preparo dos primeiros economistas surgidos em nosso país. 0 estudo da geografia comercial e estatística, da história do comércio e da indústria, de técnologia industrial e mercantil, da ciência da administração, do direito civil, do direito comercial e marítimo, da economia política, da ciência das finanças, da contabilidade do Estado, do direito internacional, da diplomacia, da história dos tratados e correspondência diplomática, do alemão, do italiano, do espanhol, da matemática superior, da contabilidade mercantil comparada e o exercitamento nas atividades do Banco Modêlo disciplinas e atividades previstas naquele plano de curso, definem-se como a primeira iniciativa no campo de formação profissional dos economistas, ainda que se pretendesse habilitar agentes consulares, técnicos em administração de companhias de seguros e chefes de contabilidade, de estabelecimentos bancários e de grandes emprêsas comerciais.

\section{EVOLUÇÃO DO ENSINO ECONÓMICO}

Das primeiras medidas pertinentes ao curso superior de comércio é que veio a resultar em nosso país o lento e gradual desenvolvimento do ensino superior de ciências econômicas e administrativas. As contingências por que passávamos no início do século $\mathrm{XX}$ explicam, em parte, a pequena receptividade do curso superior então reconhecido em meio a uma clientela atraída e ofuscada pela tradição do prestígio das mais antigas carreiras liberais. Ainda assim, em 1919, a Academia de Comércio do Rio de Janeiro transformava o antigo curso superior de comércio em Faculdades de Ciências Políticas e Econômicas.

Enquanto em nosso país se consignava êsse trabalho pioneiro, em países outros com maior desenvolvimento cultural e econômico, processava-se fenômeno análogo. Na Inglaterra, por exemplo, se a Real Sociedade de Economia funcionava desde 1890, a Faculdade de Ciências Políticas e Econômicas de Londres só teve seu início em 1898, enquanto na Alemanha, faculdades idênticas se observam, a partir de 1901, em Berlim, 
Heildeberg, Frankfurt e Colónia. Na Itália, os cursos superiores de economia tinham início na Universidade de Milão, ao passo que na Bélgica as Escolas Superiores de Ciências Econômicas, em 1901, se apresentam nas Universidades de Bruxelas, Gand e Liège. $\mathrm{O}$ mesmo se pode sentir nos demais países como a Suíça, os Estados Unidos, a França, o México, e a Argentina, em que, em 1910, se criava o Instituto de Altos Estudos Comerciais, ao passo que em 1913 surgia a Faculdade de Ciências Econômicas da Universidade de Buenos Aires. 0 interêsse pelo ensino superior de economia é ainda perceptível no Primeiro Congresso Americano de Expansão Econômica e Ensino Comercial efetuado em Montevidéu no ano de 1919, Congresso em que o Brasil teve atuação destacada. A expansão das emprêsas, o sentido da racionalização do trabalho, a ampliação dos mercados e a técnica de administrar influiram no sentido de valorizar os cursos superiores de economia, que se incumbiram de preparo de um novo tipo de profissional de nível universitário: o economista. Já em 1926, o decreto n. ${ }^{\circ} 17.329$ estruturava com segurança êsse curso superior que se evidencia com um admirável plano de estudos. A entrosagem entre a economia e a administração caracteriza-se em seu currículo, em que se podem notar a Contabilidade Administrativa e de Custo Industrial, Contabilidade Comercial e Bancária, o Direito Constitucional e Administrativo, a Ciência de Administração, a Psicologia aplicada ao comércio, ao lado de um grupo de disciplinas em que, v. g., ainda se inscreviam entre outras a Economia Política, a Ciência das Finanças, o Direito Constitucional, o Civil, o Comercial e o Internacional, a Diplomacia e a História dos Tratados. A formação de economistas começa realmente a despertar interêsse sòmente a partir de 1922, quando se diplomou a primeira turma na Capital da República. É digno de nota, no período subsequente, o esfôrço dos pioneiros que almejavam incluir na Universidade do Rio de Janeiro o ensino superior de ciências econômicas. Atento ao desenvolvimento cultural do país, o Estado Brasileiro, pelo Decreto-lei n. ${ }^{\circ} 20.158$, de 1931, dava novo impulso ao ensino comercial e econômico, possibilitando-lhes a expansão e o aprimoramento. Já então se podia perceber, nos principais centros do país, maior interêsse pelos 
cursos de formação comercial e econômico. Discorrendo, em seu discurso aos economistas diplomados pela Faculdade da Bahia, o Ministro Francisco Campos tinha, então, oportunidade de expender conceitos magistrais como por exemplo:

“a) a passagem da economia de consumo à economia de produção deu à vida humana uma tal densidade de problemas sociais, técnicos, políticos e jurídicos que os estudos econômicos constituem hoje uma das mais necessárias e indispensáveis preparações da mocidade, seja qual fôr a carreira a que se destina e, muito particularmente, se fôr a sua escolha a de indústria e comércio.

b) nota-se o desequilíbrio existente entre a nossa já incipiente vida econômica e a ausência de uma educação adequada às novas formas de atividade comercial e industrial, para as quais em todo o mundo haviam sido criadas categorias especiais de escolas, destinadas à racionalização do trabalho intelectual na indústria e no comércio, ainda entregue entre nós ao acaso das vocações e ao empirismo do aprendizado rotineiro.

c) sòmente uma educação especializada e técnica pode preparar o homem para as funções do mercado, com os seus problemas próprios, os seus tipos particulares de atividade social e econômica, os seus processos técnicos definidos e inconfundíveis.

d) só a nação que tem o mercado aparelhado, apercebido de órgãos e instrumentos perfeitamente adaptados às funções de sua vida econômica, é que se pode dizer realmente emancipada e autônoma. A emancipação política será, apenas, um ente de razão, se o mercado econômico não se diferencia e organiza na mesma latitude, em que se diferencia e organiza a vida política. Um país sem organização industrial e comercial, com tôda a majestade de suas dragonas, os seus parlamentos, as suas declarações de direitos, nunca poderá ter a densidade política que transforma os países em nações".

Entre 1931 e 1945, prosseguiu, com segurança, o trabalho dos que se dedicavam ao ensino superior de ciências econômi- 
cas e administrativas, observando-se maior procura das faculdades que cuidavam do preparo dos economistas. Finalmente, em 1945, o Decreto-lei n. ${ }^{0} 7.988$, elaborado com audiência aos líderes de classe, trouxe para o ensino superior de ciências econômicas rumos ainda mais definidos, situando-o no nível em que deveria estar como curso de interêsse das diversas Universidades. Desde então, mais de 30 faculdades se incumbem do preparo de economistas, integrando muitas delas as próprias universidades oficiais, com o que em definitivo se verificou a valorização de vossa profissão, mais ainda reforçada com a regulamentação federal do seu exercício.

\section{IMPORTÂNCIA DO ECONOMISTA}

Integrantes de um grupo profissional surgido nos últimos cinquenta anos como resultado da própria evolução social e econômica, a escolha que fizestes denota o vosso espírito pioneiro. Podendo orientar-vos para outras carreiras, cujo campo profissional e cuja tradição de prestígio de há muito se apresentam definidos, preferistes, atendendo à vossa própria vocação e aos interêsses do país, seguir como vanguarda de uma nova profissão de que muito se espera no que respeita ao nosso desenvolvimento cultural e econômico. $\mathrm{O}$ extraordinário impulso de nossa economia, a abertura de novas rotas para o comércio no mercado interno, a exploração de novas riquezas, a admirável expansão industrial que nos atinge, o aperfeiçoamento do seguro social, as exigência da legislação social e trabalhista, a necessidade de maior cautela do Estado em seu programa de ação, os problemas pertinentes à elevação do padrão de vida, a economicidade dos serviços públicos, os reclamos advindos de uma concorrência cada vez maior, os aspectos novos da psicologia das relações humanas, tudo isto se reune e se impõe como um vasto e incomensurável campo de trabalho à espera de economistas que o movimentem. Se consideramos a emprêsa particular, com suas múltiplas características e relações, aí encontraremos oportunidade para a valiosa cooperação do grupo profissional a que pertenceis, seja no setor da administração em geral, no aperfeiçoamento dos processos de compra, fabricação 
e venda, na ampliação dos mercados, na propaganda, na publicidade, no levantamento dos custos, na melhoria das condições de trabalho, ou em sua racionalização, seja no que se relaciona com a competição mercantil, com a legislação fiscal e trabalhista, ou com o aumento do rendimento dos patrimônios. Se examinarmos as múltiplas atividades do Estado, na atual conjuntura econômica, encontraremos ainda maiores oportunidades para a ação profissional dos economistas. $O$ trabalho objetivo no campo da economia, não só quanto aos estudos dos problemas que lhe dizem respeito, como, e sobretudo, na administração de seus empreendimentos é da responsabilidade dos economistas, cuja profissão se impõe pela qualidade de serviços especializados de que se incumbe, pelo cunho científico de que se reveste, pelo excepcional significado de sua atuação no que tange à prosperidade coletiva.

Estais perante o complexo sócio-econômico, como o médico em face do organismo humano, que lhe cabe preservar, mantendo-o hígido e produtivo. Daí ser a formação básica do economista ministrada através de um plano de estudos em que se realizam economia e administração, corporificando-se, na forma do Decreto-lei n. ${ }^{0} 7.988$, de 22 de setembro de 1945, em um mesmo objetivo essencial: o surgimento de um profissional com visão ampla dos problemas econômicos e financeiros, senhor das técnicas administrativas do planejamento, da supervisão, do comando e do contrôle. Como o médico é obrigado, na fixação de um diagnóstico, na determinação de uma terapêutica, a movimentar tôda uma série de conhecimentos sôbre o todo que é o organismo humano, vós outros tereis de possuir, e o possuís, uma sólida preparação básica de economista.

Prossegue, no entanto, a evolução. E da mesma maneira como as escolas superiores encaram o problema das especializações, após a formação básica geral, devem as Faculdades de Ciências Econômicas cuidar dos cursos de pós-graduação, em que os trabalhos de seminário e os estágios possam constituir base obrigatória para 0 aperfeiçoamento na administração especializada, para os estudos metodológicos da investigação econômica e outras de maior profundidade indispensáveis ao pleno exercício da profissão do economista. 
Sei que em vossos órgãos de classe e de algumas faculdades já se processa êsse movimento visando aos cursos de especialização ou de extensão universitária.

Não direi, com aquele espanto que confessava Garcia Morente, que, no mundo moderno, com a vitória do interêsse público sôbre o interêsse privado, tudo é economia e administração. Mas, direi que sem o conhecimento delas, ficaremos na imprevidência e na incapacidade.

Quem lê certos teóricos da racionalização econômica, fica realmente apreensivo com o destino das liberdades. A pretexto de fazê-la o Estado vai se tornando cada vez mais centralizador e absorvente e por traz dêle cria-se uma burocracia fabulosa, parasitária, distribuidora de privilégios e iniquidades. A idéia de colocar-se na direção do Estado um gerente, como se o Estado fôsse uma emprêsa industrial fêz com que um notável estudioso do problema, mostrasse ou demonstrasse que êsse caminho levaria, por certo, a um extremado autoritarismo.

O fato é que, como demonstrou Hayek, o caminho da liberdade, depende da solução dêsse problema, de forma que a livre empreza, despida do livre abuso, possa manter-se, em meio do interêsse público.

Num país em formação como o nosso, cuja experiência democrática é realizada em terreno difícil e em clima de inesperadas tormentas, - essa ameaça assume proporções graves.

Cabe aos mestres e aos estudiosos da economia e administração concorrer decisivamente para a solução dêsse problema, colocando o seu saber e o seu amor à liberdade a serviço dessa causa, que é a causa também da própria civilização. 